\title{
Study on the Effects of Acepromazine in Combination with Ketamine and Ketamine Alone in Local Breed Dogs
}

\author{
Gebremedhin Yohannes*1, Guesh Negash ${ }^{2}$, Hagazi Fantay ${ }^{2}$ \\ ${ }^{1}$ College of veterinary medicine, Hawassa University,Ethiopia. \\ ${ }^{2}$ College of veterinary medicine, Mekelle University, Ethiopia
}

Received: 制: September 06, 2018; Published: 制: October 09, 2018

*Corresponding author: Gebremedhin Yohannes, College of veterinary medicine, Hawassa University, PO Box 5, Hawassa, Ethiopia

\begin{abstract}
An experimental study was conducted to evaluate the effects of ketamine alone and with acepromazine combination on anesthetic parameters; on physiological and hematological parameters to choose a suitable general anesthetic combination for use in surgical procedures in local breed of dogs in Mekelle, Ethiopia. The experimental study was carried out on ten local breed of dogs and were randomly divided in to two groups with five dogs in each group. Data was collected for analyzing physiological effects of anesthetic combinations; anesthetic effects and hematological effects using physical recording and laboratory analysis. The results of this study showed duration of general anesthesia was ( $62.8 \pm 2.28 \mathrm{~min})$ and animal recovered $(72.8 \pm 2.28 \mathrm{~min})$ in acepromazine -ketamine combination whereas duration of general anesthesia was ( $30 \pm 1.05 \mathrm{~min})$ in ketamine alone. The result also showed that the physiological and hematological parameters remained significantly unchanged during the anesthesia in both groups. Therefore, relation duration of action, acepromazine and ketamine combination was a suitable choice for undertaking of surgical operations in dogs of local breed for longer duration of action i.e $(62.8 \pm 2.28 \mathrm{~min})$. Further studies on several other anesthetic combinations i.e. (acepromazine + xylazine + ketamine and acepromazine + diazepam + ketamine) on local breed of dogs and several other anesthetic combinations may be conducted.

Abbreviations: AK: Acepromazine- Ketamine; ANOVA: Analysis of Variance; CSA: Central Statistical Agency; DLC: Differential Leukocyte Counts; EDTA: Ethylene Diamine Tetra acetic acid; GABAA: Gamma-Amino Butyric Acid Type A receptors; HbC: Hemoglobin Concentration; IM: Intramuscular; Kg: Kilo gram; Mg: milligram; PCV: Packed Cell Volume; SD: Standard Deviation; SPSS: Statistical Package for Social Sciences; TEC: Total Erythrocyte count; TLC: Total Leukocyte count
\end{abstract}

\section{Introduction}

Ketamine is combined with an alpha-2-agonist (e.g. xylazine) a benzodiazepine (e.g. diazepam) or a phenothiazine tranquillizer (e.g. acepromazine) to enhance muscle relaxation, analgesia, to prevent seizures/convulsions and prolong the duration of anesthetic effect. It is associated with a rapid onset, good to excellent sedation of one to two hours duration, excellent analgesia and smooth recovery. The analgesia and sedation are due to central nervous system depression and the muscle relaxation is due to the central inhibition of intraneural transmission [1]. Ketamine is poor in visceral analgesia. However, it can be used in combination with xylazine or diazepam to provide good visceral analgesia in case of abdominal surgery (including ovariohysterectomy) and thoracic surgery. Pain is an unpleasant sensory or emotional experience most commonly associated with potential tissue damage. The sensation of pain is a consequence of the activation of specialized receptors and neurological pathways after such pain stimuli $[2,3]$.

Acepromazine possesses antiemetic, anticonvulsant, antispasmodic, hypotensive and hypothermic properties and its administration produces muscle relaxation and no analgesic effect [4]. It has prolonged duration of effect and is associated with hypotension secondary to marked peripheral vasodilatation and response variability (Hall et al. 2001). The administration of acepromazine in combination with ketamine has distinct advantages. Acepromazine reduces the dosage of ketamine needed for a given period of analgesia, and increases the degree and duration of muscle relaxation, and prevents reflex movements of the limbs. Acepromazine prolongs standing and full recovery times. It induces mild to moderate tranquilization, muscle relaxation and a decrease in spontaneous activity attributable principally to central dopaminergic antagonism. Acepromazine effectively prevents cardiac dysrhythmia and ventricular fi brillation in dogs during barbiturate and halothane anesthesia [5].

Studies on acute pain in clinical cases have most often evaluated the effects of surgical trauma on animals, while prevention and pain management are the key issues in anesthesia $[1,4,6]$. When pain is not appropriately managed, it is not only an animal welfare issue, but it can also have many detrimental effects which can impact the patient recovery [7]. A variety of physiological changes also occur in response to pain such as increases in heart rate, respiratory rate, blood pressure and body temperature $[6,8,9]$. Ketamine is rarely used alone because of its association with poor muscle relaxation, tachycardia and catalepsy or muscle rigidity. Therefore, 
it is commonly used in combination with xylazine, diazepam and acepromazine to minimize the adverse effects. Moreover, there are different breed of dogs which require proper anesthetic medicament combination. However, there are limited, or no experiments carried out to determine a specific anesthetic combination in relation to the local breed of dogs in the study area. Hence, determining the effects of the ketamine in combination with other sedative agents may help to come out with the safest combination for surgical procedures in local breed of dogs. Therefore, the purpose of this study is to evaluate the anesthetic, hematological and physiological effects of ketamine alone and ketamine-acepromazine combination for use in surgical procedures in local breed of dogs in Mekelle, Ethiopia.

\section{Materials and Methods}

\section{Study Area}

The present study was conducted from November 2016 to April 2017 in Mekelle, Tigray, Ethiopia. Mekelle is the capital of Tigray region located about 783 kilometers north of Addis Ababa with a total area of approximately 102,000 square kilo meters. Its geographic location is $13032^{`} \mathrm{~N}$ latitude and 39033`E longitude with human population of about 215,546 . It has an average altitude of 2200 meter above sea level with a mean minimum and maximum monthly temperature of 8.7 degree Celsius and 26.8 degree Celsius respectively. The annual average rainfall of Mekelle is 600 millimeters and more than 70 percent of it falls between the months July and August. The long dry season extends from October to May [10].

\section{Study Population}

The present study was carried out on mature and apparently healthy local breed of dogs weighing between 10-15 $\mathrm{kg}$ and aged between 2-4 years. Dogs were declared healthy based on physiologically normal parameters i.e. rectal temperature, heart rate, respiratory rate, and capillary refill time.

\section{Sample Size}

The present study was carried out on ten mature and apparently healthy local breed of dogs (six males and four females).

\section{Sampling Technique}

Ten dogs were randomly divided in to two groups, an experimental group with five dogs (three males and two females) in each group and one control group with five dogs (three males and two females) in each group.

\section{Experimental Design and Procedure}

Ten (10) local breed of dogs were purchased, of which five dogs were randomly assigned to an induction regimen of ketamine alone (control group) and the other five dogs were assigned to ketamineacepromazine combination (experimental group). The dogs were housed individually in a kennel, fed meat and bread. Prior to anesthesia, each dog was withheld of food and water for 12 and 6 hours respectively. These dogs were placed in a quiet kennel and left undisturbed. Heart rate, respiratory rate and temperature were recorded prior to premedication. Blood samples were taken prior to premedication. All dogs were premedicated with atropine sulphate at $0.04 \mathrm{mg} / \mathrm{kg}$ body weight subcutaneously for the reduction of salivary and bronchial secretions fifteen minutes before induction of anesthesia with ketamine alone and with acepromazine.

\section{Administration of drugs}

a) Group 1-control group (ketamine alone): First all dogs were premedicated with atropine sulphate at $0.04 \mathrm{mg} / \mathrm{kg}$ body weight subcutaneously. After fifteen minutes of premedication, a combination of acepromazine and ketamine were administered at two different doses of ketamine at $5 \mathrm{mg} / \mathrm{kg}$ and $10 \mathrm{mg} / \mathrm{kg} \mathrm{IM}$ with one-week interval between trials.

b) Group 2- experimental group (ketamine acepromazine combination): First all dogs were premedicated with atropine sulphate at $0.04 \mathrm{mg} / \mathrm{kg}$ body weight subcutaneously. After fifteen minutes of premedication, a combination of acepromazine and ketamine at two different doses acepromazine and ketamine at $5 \mathrm{mg} / \mathrm{kg}$ and $0.01 \mathrm{mg} /$ $\mathrm{kg}$ respectively and again at $10 \mathrm{mg} / \mathrm{kg}$ and $0.05 \mathrm{mg} / \mathrm{kg}$ intramuscularly respectively with one-week interval between trials.

\section{Monitoring of Post Intervention}

After administration of the ketamine alone and with acepromazine dogs of all groups were kept under close observation. Induction period, duration of anesthesia and recovery period were recorded. Rectal temperature, respiratory rate, and heart rate were recorded every 5 minutes interval after administration of the anesthetic combinations.

\section{Hematological and Physiological Parameters}

Three ml of blood sample were collected from cephalic vein of each experimental dog prior to administration of the premedication (atropine sulphate) and 30-45 minutes after administration of the anesthetic agents; because maximum effects occurred at 30-45 minutes. Immediately after collection, the blood samples were transferred in a sterile test tube containing Ethylene Diamine Tetra acetic acid (EDTA) as anticoagulant for estimation of Packed Cell Volume, White blood cells, Hemoglobin concentration, red blood cells and differential leukocyte counts according to the procedures of [11]. Physiological parameters like heart rate, respiratory rate and rectal temperature were measured every five minutes after administration of the anesthetic combinations.

\section{Data Collection}

Data were collected on physiological effects (heart rate, respiratory rate and rectal temperature), anesthetic effects (induction period, duration of anesthesia, recovery period,) and hematological effects (packed cell volume, red blood cells, white blood cells, hemoglobin concentration and differential leukocyte counts.

\section{Data Analysis}

The recorded data was entered Microsoft excel sheet and analyzed to Mean \pm SD (Standard Deviation) using Statistical Package for Social Sciences (SPSS) version 17.0 [12]. Paired t-test was used to compare physiological and hematological parameters taken before and during the administration of the drug combination for each group. One-Way Analysis of Variance 
(ANOVA) at 95\% confidence interval (CI) was used to determine the level of significant difference in mean values among three groups; to compare the means of induction time, duration of anesthesia and recovery time between the groups. Values of $p \leq 0.05$ were considered as statistically significant and Values of $p>0.05$ was considered as non-significant.

\section{Results}

\section{Anesthetic Effects of Ketamine alone and Ketamine- Acepromazine Combination}

In this study, the duration of action ketamine alone at a respective dose of $5 \mathrm{mg} / \mathrm{kg}$ and $10 \mathrm{mg} / \mathrm{kg}$ body weight given intramuscularly were $30 \pm 1.05$ minutes, $25 \pm 1.05$ minutes, respectively, whereas the recorded onset of action, duration of action and recovery time of the anesthetic combination of acepromazine - ketamine at 0.01 $\mathrm{mg} / \mathrm{kg}$ and $5 \mathrm{mg} / \mathrm{kg}$ body weight given intramuscular, respectively were $13 \pm 2.12,62.8 \pm 2.28$ and $72.8 \pm 2.28$ minutes, respectively. The recorded onset of action, duration of action and recovery time of the anesthetic combination of acepromazine - ketamine at 0.05 $\mathrm{mg} / \mathrm{kg}$ and $10 \mathrm{mg} / \mathrm{kg}$ body weight given IM, respectively were $11 \pm$ $2.12,78.6 \pm 1.67$ and $88.6 \pm 1.67$ minutes, respectively. In this study, onset of action was shorter whereas duration of action and recovery time were longer in the anesthetic combination of acepromazine ketamine at $0.05 \mathrm{mg} / \mathrm{kg}$ and $10 \mathrm{mg} / \mathrm{kg}$, respectively when compared to the anesthetic combination of acepromazine - ketamine at 0.01 $\mathrm{mg} / \mathrm{kg}$ and $5 \mathrm{mg} / \mathrm{kg}$, IM. So, in this study, the duration of anesthesia was longer in ketamine -acepromazine combination as compared with ketamine alone (Table 1).

Table 1: Effects of ketamine alone (control group), acepromazine-ketamine combination (experimental group) on onset of action, duration and recovery time.

\begin{tabular}{|c|c|c|c|c|}
\hline \multirow{2}{*}{ Anesthetic agents } & Doses (mg/kg) & Onset of action (min) & Duration of action (min) & Recovery time (min) \\
\hline \multirow{2}{*}{ Control group } & $5 \mathrm{mg} / \mathrm{kg}$ & $1.5 \pm 0.5$ & $30 \pm 1.05$ & $120 \pm 7.25$ \\
\cline { 2 - 5 } & $10 \mathrm{mg} / \mathrm{kg}$ & $1 \pm 0.4$ & $25 \pm 1.05$ & $180 \pm 7.25$ \\
\hline \multirow{2}{*}{ Experimental group } & $0.01 \mathrm{mg} / \mathrm{kg}$ and $5 \mathrm{mg} / \mathrm{kg}$ & $13 \pm 2.12$ & $62.8 \pm 2.28$ & $72.8 \pm 2.28$ \\
\cline { 2 - 5 } & $0.05 \mathrm{mg} / \mathrm{kg}$ and $10 \mathrm{mg} / \mathrm{kg}$ & $11 \pm 2.12$ & $78.6 \pm 1.67$ & $88.6 \pm 1.67$ \\
\hline
\end{tabular}

\section{Body Reflexes Activity}

\section{Rightening Reflex}

In the current study, the different body reflexes activities were assessed during the anesthesia for the sake of assessing the depth of anesthesia. The rightening reflex was elicited by squeezing or pinching a digit of fore limb and observed whether the dog flexes the leg or withdraws the digit from the investigator during the examination after administration of the anesthetic combinations. In ketamine-acepromazine combination this reflex was lost at 13 \pm 2.12132 minutes (Table 2). In this study, the rightening reflex remained unchanged throughout the anesthesia in both groups.

Table 2: Loss of body reflexes activity.

\begin{tabular}{|c|c|c|c|c|c|}
\hline \multicolumn{7}{|c|}{ Loss of body reflexes in minutes } \\
\hline $\begin{array}{c}\text { Anesthetic } \\
\text { combination }\end{array}$ & Doses(mg/kg) & Righting reflex & Palpebral reflex & Corneal reflex & Pedal reflex \\
\hline \multirow{2}{*}{ Control group } & $5 \mathrm{mg} / \mathrm{kg}$ & $1.5 \pm 0.5$ & $1.6 \pm 0.4$ & $1.6 \pm 0.4$ & $1.7 \pm 0.6$ \\
\cline { 2 - 6 } & $10 \mathrm{mg} / \mathrm{kg}$ & $1 \pm 0.5$ & $1.1 \pm 0.4$ & $1.1 \pm 0.4$ & $1.5 \pm 0.6$ \\
\hline \multirow{2}{*}{ Experimental group } & $0.01 \mathrm{mg} / \mathrm{kg}$ and $5 \mathrm{mg} / \mathrm{kg}$ & $13 \pm 2.12132$ & $13.2 \pm 2.123$ & $13.2 \pm 2.123$ & $13.7 \pm 2.223$ \\
\cline { 2 - 7 } & $0.05 \mathrm{mg} / \mathrm{kg}$ and $10 \mathrm{mg} / \mathrm{kg}$ & $13 \pm 2.12132$ & $13.2 \pm 2.123$ & $13.2 \pm 2.123$ & $13.7 \pm 2.223$ \\
\hline
\end{tabular}

\section{Palpebral Reflex}

The palpebral reflex was tested by lightly taping the lateral canthus or medial canthus of the eye and observed whether the dog blinks in response after administration of the anesthetic combinations. In ketamine-acepromazine combination this reflex was lost at $13.2 \pm 2.123$ minutes (Table 2). In this study, the palpebral reflex remained unchanged throughout the anesthesia in both groups.

\section{Corneal Reflex, Eye Position and Pupil Size}

Corneal reflex was tested by touching the cornea with a drop of sterile water and noted whether the dog blinks in response and withdraws the eye into the orbital fossa. In this observation, the time for corneal reflex loss was the same as to the time loss for palpebral reflex in all the three groups. In ketamine-acepromazine combination this reflex was lost at $13.2 \pm 2.123$ minutes (Table 2 ). In both groups the eyes remained opened, with a central and dilated pupil during the anesthesia. In this study, the corneal reflex remained unchanged throughout the anesthesia in both groups.

\section{Pedal Reflex}

The pedal reflex was elicited by squeezing or pinching a digit of hind limb and observed whether the dog flexes the leg or withdraws the digit from the investigator during the examination after administration of the anesthetic combinations. In ketamineacepromazine combination this reflex was lost at $13.7 \pm 2.223$ minutes (Tables $2 \& 3$ ). In this study, the pedal reflex remained unchanged throughout the anesthesia in both groups. 


\section{Physiological Effects of Ketamine alone and Ketamine -} Acepromazine Combination

In this study, the heart was decreased non- significantly $(\mathrm{P}=$ 0.064) from 30 minutes up to 40 minutes after administration of the anesthetic combination of acepromazine - ketamine on both doses (Table 4). The recorded respiratory rate was decreased non- significantly ( $\mathrm{P}=0.067)$ from 10 minutes up to 40 minutes following administration of the anesthetic combination of acepromazine ketamine on both doses (Table 3). The recorded rectal temperature was also decreased non- significantly ( $\mathrm{P}=0.065)$ from 20 minutes up to 40 minutes after administration of the anesthetic combination of acepromazine - ketamine on both doses (Table 4).

Table 3: Effects of ketamine alone on heart rate (HR), respiratory rate (RR) and rectal temperature (RT) of the control group.

\begin{tabular}{|c|c|c|c|c|c|c|c|c|c|c|c|c|c|}
\hline Parameters & $\begin{array}{c}\text { Time Interval } \\
\text { in minutes }\end{array}$ & & & & & & & & & & & & \\
\hline & BA & 5 & 10 & 15 & 20 & 25 & 30 & 35 & 40 & 45 & 50 & 55 & 60 \\
\hline \multirow[t]{2}{*}{ HR (beam/min) } & $80.1 \pm$ & $85.8 \pm$ & $90.5 \pm$ & $123.3 \pm$ & $128.2 \pm$ & $132 \pm$ & $137 \pm$ & $140 \pm$ & $98.5 \pm$ & $90.3 \pm$ & $81.3 \pm$ & $81.4 \pm$ & $80.8 \pm$ \\
\hline & 2.2 & 2.23 & 2.24 & 2.34 & 2.26 & 2.28 & 2.34 & 2.35 & 2.41 & 2.47 & 2.35 & 2.24 & 2.23 \\
\hline \multirow[t]{2}{*}{ RR (breath/min) } & $23.7 \pm$ & $23.1 \pm$ & $18.6 \pm$ & $17.4 \pm$ & $17.4 \pm$ & $16.6 \pm$ & $15.7 \pm$ & $15.4 \pm$ & $15.0 \pm$ & $20.2 \pm$ & $23.2 \pm$ & $23.2 \pm$ & $23.5 \pm$ \\
\hline & 0.7 & 0.78 & 0.80 & 0.91 & 0.92 & 1.13 & 1.24 & 1.36 & 1.34 & 0.77 & 0.77 & 0.64 & 0.53 \\
\hline \multirow[t]{2}{*}{$\mathrm{R} \mathrm{T}\left({ }^{\circ} \mathrm{C}\right)$} & $37.8 \pm 0$ & $37.76 \pm$ & $37.68 \pm$ & $37.64 \pm$ & $37.45 \pm$ & $37.42 \pm$ & $37.4 \pm 0$ & $37.35 \pm$ & $37.29 \pm$ & $37.182 \pm$ & $37.68 \pm$ & $37.69 \pm$ & $37.78 \pm$ \\
\hline & 0.77 & 0.79 & 0.80 & 0.85 & 0.87 & 0.89 & 912 & 0.93 & 0.95 & 1.02 & 0.84 & 0.79 & 0.69 \\
\hline
\end{tabular}

$\mathrm{BA}=$ Before anesthesia, $\mathrm{HR}=$ Heart rate, $\mathrm{RR}=$ Respiratory rate, $\mathrm{RT}=$ Rectal temperature

Table 4: Effects of acepromazine- ketamine combination on heart rate, respiratory rate and rectal temperature of experimental dogs..

\begin{tabular}{|c|c|c|c|c|c|c|c|c|c|c|c|c|c|}
\hline Parameters & $\begin{array}{c}\text { Time } \\
\text { Interval in } \\
\text { minutes }\end{array}$ & & & & & & & & & & & & \\
\hline & BA & 5 & 10 & 15 & 20 & 25 & 30 & 35 & 40 & 45 & 50 & 55 & 60 \\
\hline \multirow[t]{2}{*}{ HR (beam/min) } & $80.1 \pm$ & $79.7 \pm$ & $79.4 \pm$ & $79.3 \pm$ & $78.1 \pm$ & $77.3 \pm$ & $74.1 \pm$ & $73.3 \pm$ & $72.4 \pm$ & $72.2 \pm$ & $79.2 \pm$ & $79.4 \pm$ & $79.7 \pm$ \\
\hline & 2.22 & 2.23 & 2.24 & 2.35 & 2.26 & 2.28 & 2.31 & 2.35 & 2.41 & 2.47 & 2.35 & 2.24 & 2.23 \\
\hline \multirow[t]{2}{*}{ RR (breath/min) } & $23.7 \pm$ & $23.4 \pm$ & $18.5 \pm$ & $17.4 \pm$ & $17.3 \pm$ & $16.6 \pm$ & $15.6 \pm$ & $15.4 \pm$ & $15.1 \pm$ & $19.3 \pm$ & $23.3 \pm$ & $235 \pm$ & $23.6 \pm$ \\
\hline & 0.73 & 0.78 & 0.80 & 0.88 & 0.91 & 1.12 & 1.22 & 1.3 & 1.3 & 0.77 & 0.77 & 0.64 & 0.53 \\
\hline \multirow[t]{2}{*}{$\mathrm{R} \mathrm{T}\left({ }^{\circ} \mathrm{C}\right)$} & $37.81 \pm$ & $37.676 \pm$ & $37.588 \pm$ & $37.54 \pm$ & $37.35 \pm$ & $37.32 \pm$ & $37.3 \pm 0$ & $37.25 \pm$ & $37.39 \pm$ & $37.282 \pm$ & $37.77 \pm$ & $37.78 \pm$ & $37.79 \pm$ \\
\hline & 0.77 & 0.78 & 0.80 & 0.85 & 0.87 & 0.89 & 912 & 0.93 & 0.95 & 1.02 & 0.84 & 0.79 & 0.69 \\
\hline
\end{tabular}

$\mathrm{BA}=$ Before anesthesia, $\mathrm{HR}=$ Heart rate, $\mathrm{RR}=$ Respiratory rate, $\mathrm{RT}=$ Rectal temperature.

\section{Hematological Effects of Ketamine alone and Ketamine -Acepromazine Combination}

In the current study, blood samples were taken before and during administration of ketamine alone and the anesthetic combinations of acepromazine ketamine for evaluating of hemoglobin concentration, packed cell volume, total erythrocyte count, total leukocyte count, neutrophils, lymphocytes, monocytes, eosinophils and basophils. In group 1 hemoglobin concentration (P $=0.066)$, packed cell volume $(\mathrm{P}=0.073)$, total erythrocyte count $(\mathrm{P}=0.069)$, total leukocyte count $(\mathrm{P}=0.079)$, lymphocyte $(\mathrm{P}=$
0.064), monocyte $(P=0.061)$, eosinophil $(P=0.074)$ and basophils $(\mathrm{P}=0.084)$ were decreased non-significantly, Neutrophils $(\mathrm{P}=$ 1.000 ) were increased non-significantly from $58.9 \pm 0.39$ to $65 \pm 0.68$ (Table 5). In group 2 hemoglobin concentration ( $\mathrm{P}=0.062$ ), packed cell volume $(P=0.065)$, total erythrocyte count $(P=0.067)$, total leukocyte count $(\mathrm{P}=0.078)$, lymphocyte $(\mathrm{P}=0.084)$, monocyte $(\mathrm{P}$ $=0.071)$, eosinophil $(\mathrm{P}=0.0614)$ and basophils $(\mathrm{P}=0.083)$ were decreased non-significantly, on the other hand, neutrophils $(\mathrm{P}$ $=1.0211$ ) were increased non-significantly from $58.9 \pm 0.39$ to $66.58 \pm 0.34$ (Table 5).

Table 5: Effects of ketamine alone (control group), ketamine-acepromazine combination (experimental group) on hematological parameters.

\begin{tabular}{|c|c|c|c|c|c|c|c|c|c|c|}
\hline Anesthetics & & & & & & & & & \\
\hline & & HBC & PCV & TEC & TLC & NTP & LYM & MN & EOS & BAS \\
\hline \multirow{2}{*}{\begin{tabular}{c} 
Control group \\
Before \\
\cline { 2 - 11 }
\end{tabular}} & $\begin{array}{c}\text { During } \\
\text { anesthesia }\end{array}$ & $14.9 \pm 0.25$ & $42.3 \pm 0.25$ & $6.4 \pm 0.25$ & $10.3 \pm 0.25$ & $58.9 \pm 0.39$ & $29.9 \pm 0.53$ & $7.4 \pm 0.25$ & $3.5 \pm 0.27$ & $0.9 \pm 0.13$ \\
\hline $\begin{array}{c}\text { Experimental } \\
\text { group }\end{array}$ & $\begin{array}{c}\text { Before } \\
\text { anesthesia }\end{array}$ & $14.2 \pm 0.24$ & $42.2 \pm 0.24$ & $6.2 \pm 0.24$ & $10.2 \pm 0.24$ & $58.9 \pm 0.39$ & $29.8 \pm 0.52$ & $7.2 \pm 0.24$ & $3.4 \pm 0.26$ & $0.8 \pm 0.133$ \\
\hline & $\begin{array}{c}\text { During } \\
\text { anesthesia }\end{array}$ & $12.63 \pm 0.29$ & $40.69 \pm 0.27$ & $4.76 \pm 0.20$ & $7.79 \pm 0.19$ & $66.58 \pm 0.34$ & $26.4 \pm 0.38$ & $5.7 \pm 0.16$ & $2.1 \pm 0.21$ & $0.22 \pm 0.13$ \\
\hline
\end{tabular}

Cite this article: Gebremedhin Yohannes, Guesh Negash, Hagazi Fantay. Study on the Effects of Acepromazine in Combination with Ketamine and Ketamine Alone in Local Breed Dogs. Biomed J Sci\&Tech Res 9(5)-2018. BJSTR. MS.ID.001851. DOI:10.26717/ BJSTR.2018.09.001851. 
$\mathrm{HBC}=$ Hemoglobin concentration, $\mathrm{PCV}=$ Packed cell volume, TEC $=$ Total erythrocyte count, TLC $=$ Total leukocyte count, $\mathrm{NTP}=$ Neutrophil, LYM = Lymphocyte, $\mathrm{MN}=$ Monocyte, $\mathrm{EOS}=$ Eosinophil, BAS = Basophil.

\section{Discussion}

Ketamine is rarely used alone because of its association with poor muscle relaxation, tachycardia and catalepsy or muscle rigidity and it is therefore commonly used in combination with xylazine, diazepam and acepromazine to minimize the untoward effects the highest duration of anesthesia was observed in the dogs of Group 2 (experimental group) as compared to group 1 (control group). This might be due to wide-distribution of acepromazine and ketamine combination in the body, because they are highly soluble in lipid and can be redistributed into muscles and adipose tissues [13]. This finding difference in the present study from previous studies might be due to difference in breed and physiological status of the dogs or might be due to difference in dose of the anesthetic agents. The decrease in body temperature after the administration of ketamine alone and the acepromazine-ketamine, could be explained by blocking of the hypothalamic thermoregulatory center. The decrease in heart rate could be attributed to inhibition of the release of the neurotransmitter noradrenalin or depression of the sympathetic activity.

The decrease in respiratory rate could be attributed to depression of the respiratory center by the ketamine alone, acepromazine-ketamine [14]. The non-significant decrease in heart rate, respiratory rate and rectal temperature in the present study when compared to other studies might be due to difference in breed and physiological status of the dogs or might be due to difference in dose of the sedative agents. In the present study, the average duration of anesthetic induction after administration of acepromazine - ketamine at $0.01 \mathrm{mg} / \mathrm{kg}$ and $5 \mathrm{mg} / \mathrm{kg}$, and ketamine alone at $5 \mathrm{mg} / \mathrm{kg}$ respectively were $62.8 \pm 2.28$ and $30 \pm 1.05$ minutes, respectively. This finding agrees with the studies by [15] reported 35.7 minutes of the average duration of anesthesia after administration of acepromazine and ketamine combination, but the onset of action was slower in the present finding when compared to observations separated by [15] he had reported average 4.2 minutes after administration of acepromazine and ketamine combination. The slower onset of action in the present finding when compared to the other studies might be due to difference in breed of the dog or due to difference in physiological status of the dog.

In this study, heart rate was increased significantly at 30-45 minutes after administration of ketamine alone but decreased non-significantly at 30-45 minutes, respiratory rate was decreased non-significantly at 10-45 and rectal temperature was decreased non-significantly at 20-45 minutes after administration of acepromazine at $0.05 \mathrm{mg} / \mathrm{kg}$ and ketamine at $10 \mathrm{mg} / \mathrm{kg}$ body weight intramuscularly. Relatively similar finding was reported by White et al (2001) who found decreased respiratory rate at the first 30 minutes after administration of the acepromazine at 0.03 $\mathrm{mg} / \mathrm{kg}$ and ketamine at $5 \mathrm{mg} / \mathrm{kg}$ body weight intramuscularly on ten healthy dogs. After administration of ketamine alone, and with acepromazine -the hemoglobin concentration, packed cell volume, total erythrocyte count, total leukocyte count, lymphocyte, monocyte, eosinophil and basophils were decreased nonsignificantly, but neutrophils were increased non-significantly. Pooling of circulating blood cells in the spleen and other reservoirs secondary to decreased sympathetic activity could be the reason for a decrease in hemoglobin concentration, packed cell volume, total erythrocyte count, total leukocyte count, lymphocyte, monocyte, eosinophil and basophils [16].

The decrease in hemoglobin concentration, packed cell volume, total erythrocyte count, total leukocyte count, lymphocyte, monocyte, eosinophil and basophils after administration of the acepromazine and ketamine combination might be attributed to the shifting of fluid from extravascular compartment to intravascular compartment to maintain normal cardiac output in the dogs [17]. This finding agrees with the findings of [18-25] who had reported decreased the hemoglobin concentration, packed cell volume, total erythrocyte count, total leukocyte count, lymphocyte, monocyte, eosinophil and basophils and increased neutrophils after administration of acepromazine at $0.04 \mathrm{mg} / \mathrm{kg}$ and ketamine at $10 \mathrm{mg} / \mathrm{kg}$ combination in dogs.

\section{Conclusion}

Ketamine is rarely used alone because of its association with poor muscle relaxation, visceral analgesia, tachycardia and catalepsy or muscle rigidity. Therefore, it is commonly used in combination with xylazine, diazepam and acepromazine to enhance muscle relaxation, to provide good visceral analgesia in case of abdominal surgery (including ovariohysterectomy) and thoracic surgery, to prevent seizures/convulsions and to prolong the duration of anesthetic effect. The study was conducted on 10 mature and apparently healthy local breed of dogs which were randomly grouped in to Group I and Group II. All dogs were premedicated using atropine $(0.04 \mathrm{mg} / \mathrm{kg} \mathrm{BW}, \mathrm{S} . \mathrm{C})$ [26-29]. After 15 mints premedication, anesthesia induced with ketamine alone, and acepromazine-ketamine $(5 \mathrm{mg} / \mathrm{kg} /-10.0 \mathrm{mg} / \mathrm{kg}, 0.01-.05+5-$ $10 \mathrm{mk} / \mathrm{kg}$ BW, I.M) for Group I, and Group II respectively.

The anesthetic parameters; induction time, duration of anesthesia recovery period, the physiological parameters; temperature, heart rate, respiratory rate, and the hematological parameters; packed cell volume, total erythrocyte count, total leukocyte count, hemoglobin determination were recorded and analyzed in both groups and all the anesthetic parameters were found statistically significant but the physiological and hematological parameters were statistically non-significant in both groups. The results of the present study concluded that acepromazine-ketamine combination is useful anesthetic protocol for rapid induction, prolonged duration of anesthesia; acepromazine-ketamine combination is useful anesthetic protocol for short duration of anesthesia and rapid recovery. All drug combinations do not affect the physiological and hematological parameters of the animals during the study time and all of them can be safe for surgical procedures if used safely and appropriately. However, further studies on several other anesthetic combinations 
i.e. (acepromazine + xylazine + ketamine and acepromazine + diazepam + ketamine) on local breed of dogs and several other anesthetic combinations may be conducted.

\section{References}

1. Muir W (2008) Cylohexamine drug mixtures: The pharmacology of ketamine and ketamine combination drugs Proceedings of second International Congress of Veterinary Anesthesia. Veterinary Publishing Co Santa Barbara 4: 5-14.

2. Mathews A (2000) Pain assessment and general approach to management. Veterinary Clinical. North America Small Animal Practice 30(4): 729-755.

3. Junior E, Santos J, Russo C, Elsensaut P, Headley A (2009) Evaluation of cortisol levels of dogs anesthetized with sevoflurane and premedicated with butorphanol 30(2): 425-433.

4. Tranquilli J, Thurmon C, Grimm A (2007) Lumb and Jones' Veterinary Anesthesia and Analgesia. In : Tranquilli J, Thurmon C, Grimm A (Eds.), ( $4^{\text {th }}$ edn.). Oxford: Blackwell, Oxford, United Kingdom: p. 80-105.

5. Thurmon JC, Kumar A, Link RP (2003) Evaluation of ketamine hydrochloride as an anesthetic in sheep. J Am Vet Med Assoc 162(4): 293-297.

6. Gaynor S, Muir W (2008) Handbook of Veterinary Pain Management Drugs acting on the central nervous system. In Gaynor S, Muir W (Eds.). ( $2^{\text {nd }}$ Edn.). St. Louis Mosby, United States: p. 78-109.

7. Orskov T (2010) Pain assessment in cats and dogs. Irish Journal of Veterinary science 63(6): 362-364.

8. Atalan H, Gunes V, Cihan M, Celebi F, Citil M (2002) Comparisons of xylazine + ketamine- $\mathrm{HCl}$ anaesthetic agents with acepromazine + butorphanol + ketamine combinations for their clinical, cardiovascular and respiratory effects in dogs 8: 35-40.

9. Bergamasco L, Osella C, Savarino P, Larosa G, Ozella L, et al. (2010) Heart rate variability assessment in shelter dog. Application animal Science 125(1): 56-68.

10. (2008) CSA Central Statistical Agency: Report on monthly average retail prices of goods and services. Statistics Bulletn p: 416.

11. Orpet H, Welsh P (2002) Handbook of Veterinary Nursing. Implementation a patient care plan. 1st edition, Blackwell Science Ltd, USA, 10: 244-251.

12. Winer J, Brown R, Michels K (2001) Statistical principles in experimental designs. In Winer J, Brown R, Michels K(Eds.) 3rd edition, Mcgraw hill series, United States: p. 1057.

13. Azizpour A, Hassani Y (2012) Clinical evaluation of general anesthesia with a combination of Ketamine HCL and Diazepam in pigeons. Journal of Agriculture 7: 101-105.

14. Walter H (2008): Handbook of Veterinary Pharmacology: Drugs Acting on the Central Nervous System. In Walter H (Eds.), Wiley-Blackwell, New Jersey, United States: p. 81-107.

15. Ferreira P, Dzikiti B, Zeiler E, Buck R, Nevill B, et al. (2015) Anesthetic induction and recovery characteristics of a diazepam-ketamine combination compared with propofol in dogs. Journal of the South African Veterinary Association 86(1): 1258.

16. Kilic N (2004) Physiological and hematological changes in ketamine and diazepam anesthesia in horse. Indian Journal of Veterinary 81: 396-398.

17. Wagner A, Muir W, Hinchcliffe K (2001) Cardiovascular effects of xylazine and detomidine in horse. American Journal of Veterinary Research 52(5): 651-657.

18. Mahmud A, Shaba P, Yisa H, Gana J, Ndagimba R, et al. (2014) Comparative efficacy of Diazepam, Ketamine and Diazepam-Ketamine combination for sedation or anesthesia. Journal of advances Veterinary Animal Research 1(3): 107-113.

19. Afshar S, Baniadam A, Marashipour P (2005) Effect of xylazine ketamine on arterial blood pressure, arterial blood $\mathrm{pH}$, blood gases, rectal temperature, heart rate and respiratory rate in goat. Bulletin of the Veterinary Institute in Pulawy 49(4): 481-484.

20. Amarpal P, Kinjavdekar P, Aithal A, Pawde K, Singh J, et al. (2010) Evaluation of Xylazine, Acepromazine and Medetomidine + Ketamine for general anesthesia in rabbits. Scandinavian Journal of Laboratory Animal Sciences 37(3): 223-229.

21. Demirkan Y, Gokce HY, Ozaydin D, Celebi F (2002) Comparative study of butorphanol-ketamine and xylazine -ketamine combinations for their clinical, cardiovascular and respiratory effects in healthy dogs. Turkey journal of veterinary and animal science 26(5): 1073-1079.

22. Durrani F, Ashraf M, Khan A (2009) A comparisons of the clinical effects associated with xylazine, ketamine and a xylazine-ketamine cocktail in pigeons (Columba Livia). Turkish Journal of Veterinary and Animal Science 33(5): 413-417.

23. Emami M, Sedighi R, Sarhaddi S (2010) Cardiovascular and respiratory effects of romfidine or xylazine in ketamine anesthesia in dogs. Iranian journal of veterinary surgery 36(2): 110-123.

24. Gulanber E, Baștan A, Tasal I, Aktas M, Arikan N (2001) Ketamine as general anesthesia. Journal of the faculty of veterinary medicine, Istanbul university 27(2): 401-409.

25. Kul M, Koc Y, Alkand F, Ogurtan Z (2000) The effects of xylazine-ketamine and diazepam-ketamine on arterial blood pressure and blood gases in dogs. Journal of Veterinary Research 4: 123-132.

26. Mwangi E, Mogoa M, Nguhiu J, Mulei M (2014) Effects of epidural Ketamine, Xylazine and their combinations on body temperature in acepromazine-sedated dogs. International Journal of Advanced Research 2: 336-340.

27. Naqialbayati T (2015) A comparative study between of effect of tramadol and xylazine as premedication those followed by ketamine anesthesia in dogs. Kufa journal for veterinary medical sciences 6: 2 .

28. Sindak N, Camekerten I, Ceylan C (2010) clinical evaluation of xylazineketamine anesthesia in bozova greyhounds. Journal of animal and veterinary advances 9(15): 2025-2029.

29. Wyatt D, Scott W, Richardson E (2001) The effects of prolonged ketaminexylazine intravenous infusion on arterial blood $\mathrm{pH}$, blood gases, mean arterial blood pressure, heart and respiratory rates, rectal temperature and reflexes in the dogs. Journal of Veterinary Science 39(5): 411-415. 
ISSN: 2574-1241

DOI: 10.26717/BJSTR.2018.09.001851

Gebremedhin Yohannes. Biomed J Sci \& Tech Res

(c) This work is licensed under Creative

Submission Link: https://biomedres.us/submit-manuscript.php

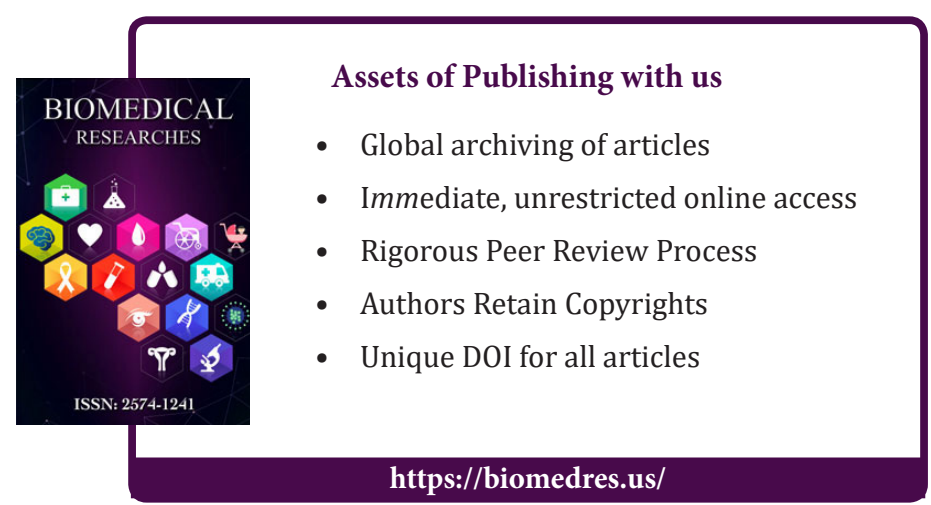

